\section{Carotid-cavernous fistula: current concepts in aetiology, investigation, and management}

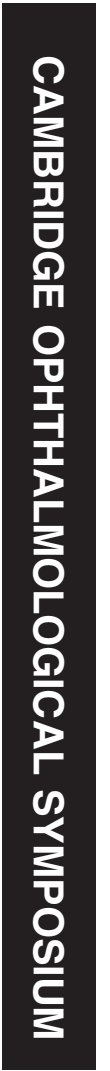

Division of NeuroOphthalmology, Wilmer Eye Institute, Johns Hopkins School of Medicine, Baltimore, MD, USA

Correspondence: NR Miller, Johns Hopkins Hospital, Woods 458, 600 N. Wolfe Street, Baltimore, MD 21287, USA

Tel: +410733 5296;

Fax: +410 5023214 .

E-mail: nrmiller@jhmi.edu

Received: 18 September 2017

Accepted in revised form: 22 September 2017

Published online:

3 November 2017
AD Henderson and NR Miller
A carotid-cavernous sinus fistula (CCF) is an abnormal communication between arteries and veins within the cavernous sinus. CCFs may be classified into four types: direct fistulas (Barrow type A) and dural, or indirect, fistulas (Barrow types B, C, and D). ${ }^{1}$ Direct fistulas are characterized by a direct connection between the internal carotid artery (ICA) and the cavernous sinus (Figure 1a). ${ }^{1}$ They are usually high-flow fistulas. Causes include penetrating or blunt trauma, rupture of an ICA aneurysm within the cavernous sinus, Ehlers-Danlos syndrome type IV, or iatrogenic interventions, including transarterial endovascular intervention, internal carotid endarterectomy, percutaneous treatment of trigeminal neuralgia, trans-sphenoidal resection of a pituitary tumour, and maxillofacial surgery. ${ }^{2-17}$

Dural CCFs typically are low-flow fistulas that consist of communications between the cavernous sinus and cavernous arterial branches (Figure 1b). Barrow type B fistulas involve meningeal branches of the ICA, Barrow type C involve external carotid branches, and Barrow type D fistulas include meningeal branches from both the internal and external carotid arteries. Spontaneous dural CCFs are usually type D. ${ }^{18}$ The artery of the inferior cavernous sinus is the most frequently implicated trunk of the ICA, but dural fistulas also may involve the meningohypophyseal trunk and its branches. The most commonly involved branch of the external carotid artery is the internal maxillary artery, with other implicated branches being the middle and accessory meningeal arteries, ascending pharyngeal artery, anterior deep temporal artery, and posterior auricular artery. ${ }^{19}$ Causes of dural fistulas include hypertension, fibromuscular dysplasia, Ehlers-Danlos type IV, and dissection of the ICA. ${ }^{20-23}$ Post-menopausal women most commonly are affected. ${ }^{19}$ 

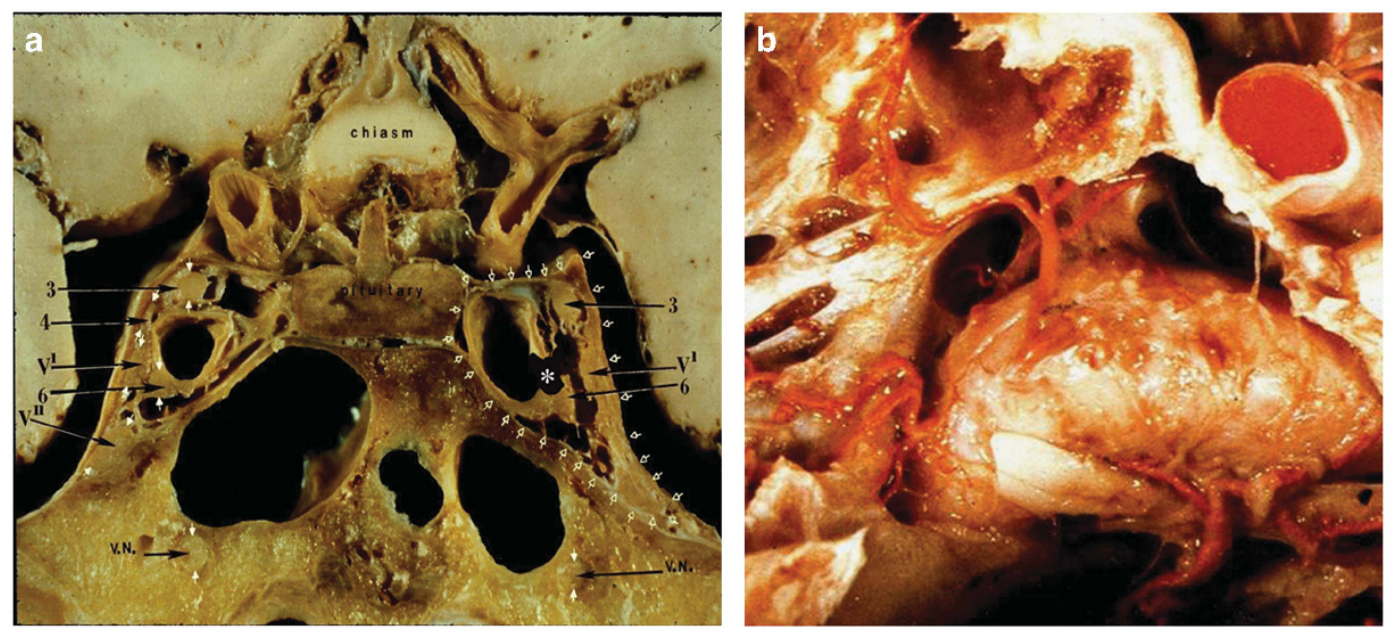

Figure 1 (a) Gross anatomic coronal section through the cavernous sinuses demonstrates the concept of a direct CCF on the left (asterisk). Open arrows delineate the left cavernous sinus. The locations of the cranial nerves within the cavernous sinus (solid arrows) emphasize the relative vulnerability to injury of the abducens nerve, which lies in the body of the cavernous sinus adjacent to the cavernous portion of the ICA. $3=$ oculomotor nerve, $4=$ trochlear nerve, V1=ophthalmic division of the trigeminal nerve, $\mathrm{V} 2=$ maxillary division of the trigeminal nerve, $6=$ abducens nerve, $\mathrm{VN}=$ vidian nerve. (b) Gross anatomic axial section showing branches of the cavernous portion of the ICA. One or more of these branches may participate in dural CCFs.

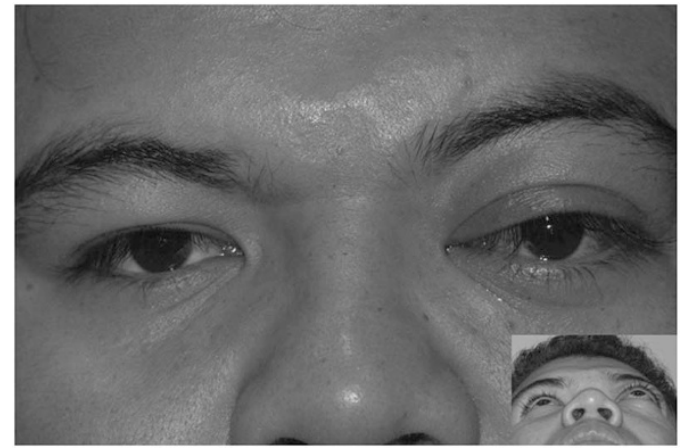

Figure 2 External photograph of a patient with a red left eye and mild left proptosis (inset) from a left-sided CCF.

The pathogenesis of dural CCFs likely involves a primary thrombosis of cavernous sinus venous outflow channels and resultant vascular alterations to provide collateral flow. ${ }^{22,24,25}$ This theory of pathogenesis is widely supported because it also accounts for the development of arteriovenous fistulas involving other dural sinuses. ${ }^{18}$ However, some authors favour a conflicting theory, which purports that dural CCFs form after rupture of one or more thin-walled dural arteries, leading to the dilation of pre-existing dural-arterial anastomoses. These anastomoses then contribute collateral blood supply, and the angiographic result is similar to that of a congenital vascular malformation. ${ }^{1,26}$

Presenting symptoms of CCFs may include a subjective bruit, diplopia, tearing, red eye, ocular foreign body

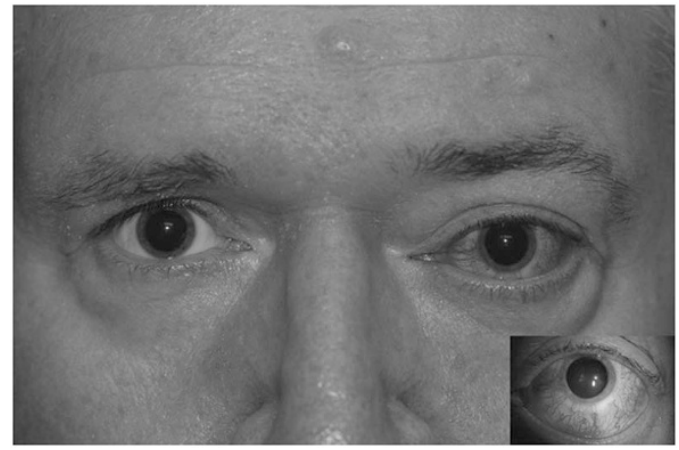

Figure 3 Left eye conjunctival and episcleral injection in a patient with a left-sided CCF. Inset shows that the injection is due to tortuous vessels containing arterial blood (ie, arterialized vessels).

sensation, blurred vision, and headache. ${ }^{1,27-31}$ Anteriorly draining fistulas are more likely to cause ocular symptoms. ${ }^{22}$ Patients with posteriorly draining fistulas may develop neurologic symptoms, such as confusion and expressive aphasia, ${ }^{22}$ as well as diplopia from isolated ocular motor nerve pareses. Clinical symptoms and signs usually present acutely in cases of direct fistula and are more indolent in dural fistulas.

Clinical signs of CCFs depend in part on whether the lesion is high flow or low flow but include proptosis (Figure 2) that may be pulsating in the setting of highflow lesions; a red eye with arterialization of the conjunctival and episcleral vessels (Figures 2 and 3); chemosis (Figure 4); strabismus due to ocular motor nerve dysfunction (Figure 5), orbital congestion, or both; an 
ocular bruit; increased intraocular pressure (IOP); stasis retinopathy or even central retinal vein occlusion in cases of significantly raised episcleral venous pressure; and optic neuropathy that may be non-glaucomatous from direct trauma or ischaemia, or glaucomatous. ${ }^{28,33}$ Although an objective bruit is more common in the setting of a high-flow fistula, it may be elicited with a Valsalva manoeuvre in some patients with low-flow fistulas. ${ }^{27,34}$ Neurogenic strabismus most commonly



Figure 4 Patient with marked left eye injection, chemosis, and proptosis from a left-sided dural CCF. The patient also has left ptosis and a dilated left pupil, consistent with an ocular motor nerve paresis caused by the fistula. presents as a sixth nerve palsy (Figure 6). 22,35,36 The relative frequency of sixth nerve involvement occurs due to the central location of the sixth nerve adjacent to the ICA within the cavernous sinus (Figure 1), placing it at higher risk of injury than the other cranial nerves that are located in the deep layer of the lateral wall of the sinus.

When there is suspicion for a CCF, in-office evaluation may include standard tonometry, pneumotonometry, ultrasonography, and/or colour Doppler imaging. Simply observing the movement of the mires during applanation tonometry can provide a clue to the presence of a CCF when there is greater movement on the side of the ocular manifestations than on the other side. Similarly, although most clinics do not have access to a pneumotonograph, pneumotonometry can be a valuable diagnostic tool, as a difference in ocular pulse amplitudes (defined as the difference between systolic and diastolic IOP) of $1.6 \mathrm{~mm} \mathrm{Hg}$ between the two eyes has been shown to be $100 \%$ sensitive and 93\% specific for a CCF (Figure 7). ${ }^{34}$ Orbital ultrasound typically reveals a dilated superior ophthalmic vein (SOV) and evidence of orbital congestion with enlarged extraocular muscles and also can be used to exclude mimickers of CCF, including orbital tumours, dysthyroid orbitopathy, orbital inflammation, and scleritis. ${ }^{37}$ Colour Doppler evaluates flow velocity and
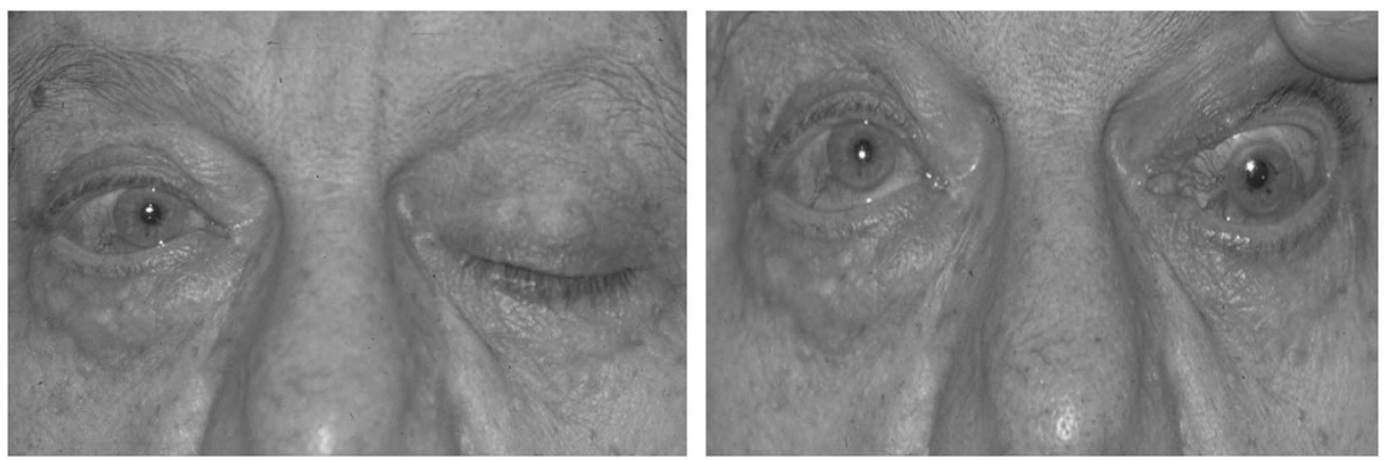

Figure 5 Left ptosis, exotropia, and dilated pupil caused by a left oculomotor nerve paresis in a patient with a left-sided dural CCF. Note bilateral dilation of conjunctival and episcleral vessels.
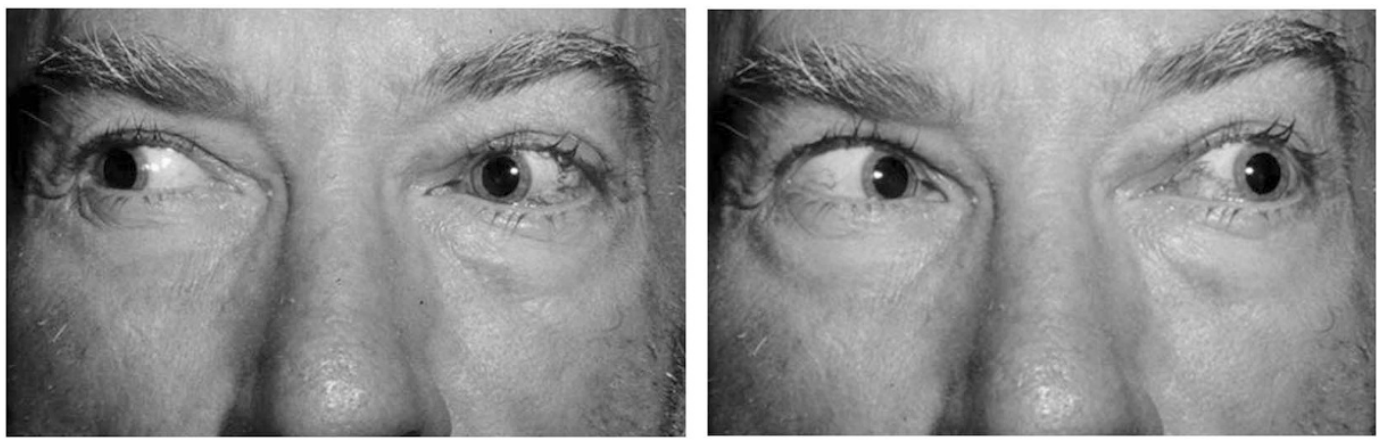

Figure 6 Left sixth nerve palsy in a patient with left-sided dural CCF. 
direction, thus indicating arterial flow in the orbital veins in cases of CCF. ${ }^{33}$ The presence of flow reversal in the SOV is suggestive of a CCF.

Patients in whom a CCF is suspected require neuroimaging that may include non-invasive computed tomographic angiography (CTA) or magnetic resonance angiography (MRA). Both techniques have high sensitivities for both direct and dural CCFs that cause visual manifestations. Chen et $a l^{38}$ performed a retrospective study of 53 patients with angiographically confirmed direct or dural CCFs. All patients underwent pre- and postcontrast-enhanced CTA and digital subtraction angiography (DSA), and 50 patients also underwent MRA. Two neuroradiologists rated detectability of the fistula by using each procedure. The investigators found that CTA did not differ significantly from DSA, with CTA having a sensitivity of 87 vs $94.4 \%$ sensitivity for DSA. The sensitivity for MRA was significantly lower than either CTA or DSA, being $80 \%$. Differences in performance among the methods depended primarily on the segmental location of the fistula along
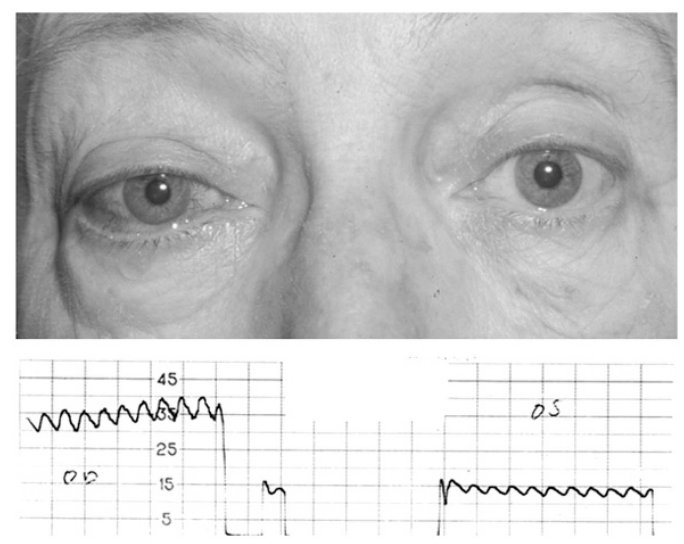

Figure 7 Pneumotonometry measurements in a patient with a right dural CCF reveal an ocular pulse amplitude of $6 \mathrm{~mm} \mathrm{Hg}$ OD compared with $2 \mathrm{~mm} \mathrm{Hg}$ OS. The difference in ocular pulse amplitude between the two eyes is $4 \mathrm{~mm} \mathrm{Hg}$, supporting the diagnosis of a CCF.
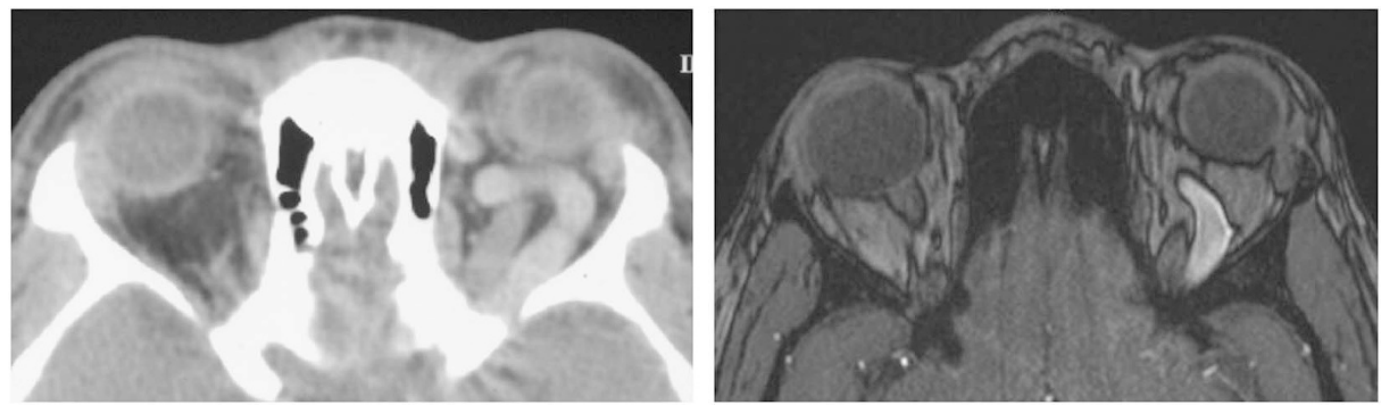

Figure 8 Axial computed tomographic scan (left) and postcontrast magnetic resonance image (right) show enlargement of the left SOV in a patient with a left-sided, anteriorly draining, CCF. the ICA. In addition, enlargement of the SOV on standard CT scanning or MR imaging (MRI), either unilaterally or bilaterally, has been found to be suggestive of a CCF (Figure 8). ${ }^{28} \mathrm{CT}$ and MRI also may show orbital congestion, with enlargement of the extraocular muscles and periorbital fat, and convexity of the lateral wall of the cavernous sinus. ${ }^{34}$ However, as these findings are not specific for a CCF, patients in whom a CCF is suspected still may require DSA, which remains the gold standard for classification and diagnosis of CCF and can be both diagnostic and therapeutic. Angiographically, high-flow fistulas show rapid filling of the cavernous sinus through the fistula with minimal or no filling of the intracranial vasculature, whereas low-flow fistulas demonstrate slower filling of the cerebral venous system through the fistula, with preserved filling of the intracranial arteries. In addition, DSA characterizes the drainage pattern of the fistula (eg, anteriorly via the SOV, posteriorly via the inferior petrosal sinus (IPS), or a combination of the two;

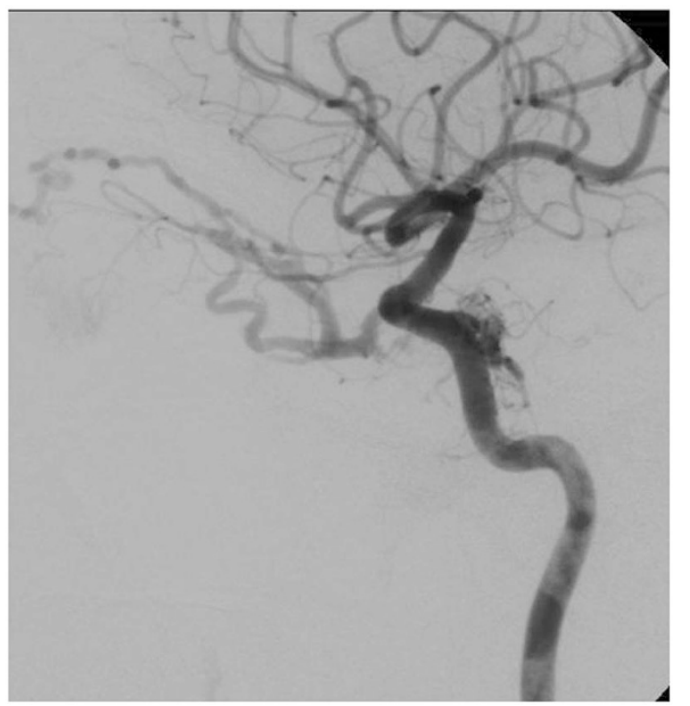

Figure 9 Selective left internal carotid arteriogram (lateral view) shows a dural CCF with drainage both anteriorly and posteriorly. 
Figure 9). It also can determine whether there is reflux into cortical veins. ${ }^{39}$

Previously, the treatment options for direct CCFs were limited to observation or treatment consisting of trapping of the fistula by ligating the cervical ICA proximal to the fistula and the intracranial ICA distal to the fistula or occlusion of the common carotid artery or ICA, either of which could result in a cerebral ischaemic event due to an induced low-flow state or an embolic event. ${ }^{1,40}$ With the development of endovascular interventional techniques, open surgical procedures are no longer preferred, the range of potential therapies has broadened, and the ICA almost always can be preserved. Endovascular treatment is less invasive and carries a lower risk of cerebral infarction, compared with ICA sacrifice. ${ }^{41}$ The ideal treatment approach depends on the arterial supply, the venous drainage, the speed of blood flow through the fistula, and the patency of the circle of Willis. ${ }^{18,42} \mathrm{~A}$ transarterial approach via the ICA is most commonly used. A guiding catheter is placed in the ipsilateral femoral artery and advanced up to the ICA, followed by introduction of a microcatheter into the cavernous ICA, then through the fistula into the cavernous sinus. The embolic material of choice, including detachable balloons, coils, n-butyl cyanoacrylate (acrylic glue), or ethylene vinyl alcohol copolymer (Onyx Liquid Embolic System, Micro Therapeutics, Inc., Irvine, CA, USA) is then injected into the cavernous sinus through the microcatheter. ${ }^{43}$ Detachable balloons commonly have been used for fistula repair. Although these balloons have not been available on the United States market since 2003, they remain available in some other parts of the world. ${ }^{20}$ Transarterial balloon placement is accomplished by directing the collapsed balloon through the fistula and into the cavernous sinus, inflating the balloon to a size large enough to completely occlude the fistulous connection, and then releasing the balloon. Since the removal of balloons from some markets, coiling has largely replaced this procedure as the endovascular treatment of choice for direct CCFs. ${ }^{43,44}$ Some authors advocate the use of acrylic glue as an embolic material due to its cost effectiveness and potential for an improved safety profile among patients at high risk for vascular injury due to connective tissue disease. ${ }^{45}$ Flow-diverting stent assistance may be used for endoluminal reconstruction in cases with large tears in the ICA wall, through which the injected embolic material could pass back into the arterial circulation, thus placing the patient at risk for embolic complications. These stents may be deployed across the ICA tear to prevent backflow of the injected material. Some authors claim that the use of flow-diverting stents also may facilitate endothelialization of the injured ICA. ${ }^{46}$ Disadvantages to the addition of a flow-diverting stent include the cost of the device and the need for postoperative antiplatelet therapy. A transvenous approach via the IPS or superior or inferior ophthalmic vein may be used in some cases where transarterial approach is not feasible. Overall, endovascular intervention offers a $90-100 \%$ cure rate with a low rate of complications ${ }^{35,45,47-49}$ and an acceptably low mortality rate of $<1 \%$. Minor transient complications, including haematoma, facial pain, and ocular motor nerve palsies, occur in $1-30 \%$ of cases. ${ }^{18}$ Major sequelae, including hemiparesis and permanent ocular motor nerve palsy, are quite rare in the general population; however, patients with Ehlers-Danlos type IV have much higher complication rates with both diagnostic and therapeutic endovascular procedures due to the underlying vascular fragility in this condition. ${ }^{4}$ In addition, some authors report often-overlooked, moderate, persistent ocular motor deficits, which they relate to coil volume, either indirectly, as a surrogate marker for the size of the initial vascular injury, or directly, via associated mass effect on the cranial nerves within the cavernous sinus. ${ }^{50}$

Treatment options for dural CCFs include observation, IOP-lowering agents, intermittent compression of the ipsilateral ICA or SOV, stereotactic radiosurgery, and endovascular intervention. As up to $70 \%$ of dural CCFs close spontaneously due to local thrombosis of the SOV propagating posteriorly, observation or conservative treatment techniques not only are acceptable but also are the preferred approaches to management in cases without high-risk features. ${ }^{20,33,37,51}$ Initially, spontaneous closure may be associated with exacerbation of the clinical symptoms and signs; in this setting, patients may require repeat angiography. ${ }^{34}$ Closure of dural CCFs also has been reported after diagnostic angiography and air travel. ${ }^{17,37,49}$ If invasive intervention is not warranted, patients may use techniques of occlusion, such as external manual carotid compression, to promote resolution of the CCF. Using the contralateral hand, the patient compresses the ICA on the involved side, thus lowering the carotid arterial pressure through the fistula. The contralateral hand is used so that if cerebral ischaemia occurs, the patient will develop a hemiparesis, and the hand will release its pressure on the artery. Compression is repeated several times per hour, for $10 \mathrm{~s}$ with each repetition initially, with progressive titration of treatment session duration to several minutes. After exclusion of patients deemed to be poor candidates for carotid compression therapy, due to decreased visual acuity or cortical venous drainage of the fistula, success rate of this procedure has been reported to be $35 \%$, with resolution occurring between 2 weeks and 7 months after initiation. ${ }^{52}$ Carotid compression is contraindicated in patients with carotid atherosclerotic disease, as they are already at risk for stroke from insufficient carotid blood flow and embolic complications. An additional at-home technique involves 
repeated compression of the SOV on the involved side. Using the thumb over the superomedial orbital rim, compression of the SOV is held for $10 \mathrm{~min}$, and the procedure repeated four to six times daily. ${ }^{53}$ Success of this procedure has been demonstrated within a 4- to 6week period in patients wishing to avoid invasive procedures, as well as in patients who have failed attempted endovascular repair. ${ }^{53}$

Although a watchful waiting approach is reasonable in many patients with a dural CCF, treatment sometimes is required to prevent long-term sequelae. Indications for intervention include uncontrollable IOP, unremitting diplopia, severe proptosis with corneal exposure, optic neuropathy, retinal ischaemia, severe bruit, and cortical venous drainage from the fistula. Endovascular treatment is first line and may be performed transarterially or transvenously. Similar to embolization of direct CCFs, embolization of dural CCFs may be accomplished using coils, acrylic glue, or Onyx, which can be used individually or in combination. ${ }^{54,55}$ Flow-diverting stents also may be used alone or in combination with coils. ${ }^{20}$ Advantages of coils include their radio-opacity and ability to be re-deployed or removed if initial placement is not ideal; however, their solid, fixed state may lead to compartmentalization within the cavernous sinus, thus producing incomplete embolization of the fistula. The liquid state of both acrylic glue and Onyx addresses this disadvantage, allowing for obliteration of even an anatomically complicated fistula with a single infusion of embolic material. ${ }^{56}$ Pathologic study has demonstrated that injection of acrylic glue triggers an acute inflammatory response in the affected vessel, leading to mural angionecrosis. This reaction is followed by a chronic granulomatous vasculitis that contributes to durability of the treatment effect. ${ }^{57}$ Some authors report a high rate of success when transarterial embolization using acrylic glue is performed as the primary approach to dural fistulas. ${ }^{31}$ Compared with glue, Onyx is more cohesive and polymerizes more slowly. These characteristics allow the neurointerventionalist to inject slowly or even discontinuously into the cavernous sinus, thus resulting in improved accuracy and reducing the need for repeated catheterizations. ${ }^{58}$ As an Onyx injection proceeds, collateral vessels not apparent on initial angiography may become visible, and injection of further embolic material can be tailored, based on the observations of Onyx during its injection. ${ }^{59}$ Endovascular treatment for dural CCFs has a lower rate of success and a higher risk of complications compared with treatment for direct CCFs. Historically, due to the frequent involvement of multiple meningeal arterial branches and the difficulty cannulating these small, tortuous branches, arterial approaches frequently have been unsuccessful in treating dural fistulas. However, with the use of Onyx, success of the transarterial approach in treating dural CCFs has increased, with one paper reporting angiographic cure rates of $87 \%$ when the agent is used alone and $79 \%$ when it is used in combination with another agent, with a $2 \%$ risk of permanent complications. ${ }^{59}$

Despite increasing success of transarterial procedures, a transvenous approach via the IPS, superior petrosal sinus, basilar plexus, pterygoid plexus, SOV, or inferior ophthalmic vein, still is preferred for most dural CCFs that require treatment (Figure 10). ${ }^{41,58,60}$ The IPS is the first-line approach, as it is the most straightforward and shortest route to the cavernous sinus. Advances in endovascular technology, including the development of variable stiffness microcatheters and guidewires, have increased feasibility of this approach such that it is now possible in the majority of patients. ${ }^{61}$ To access the IPS, a posterior approach via the internal jugular vein is used. When the IPS approach is not possible due to anatomic
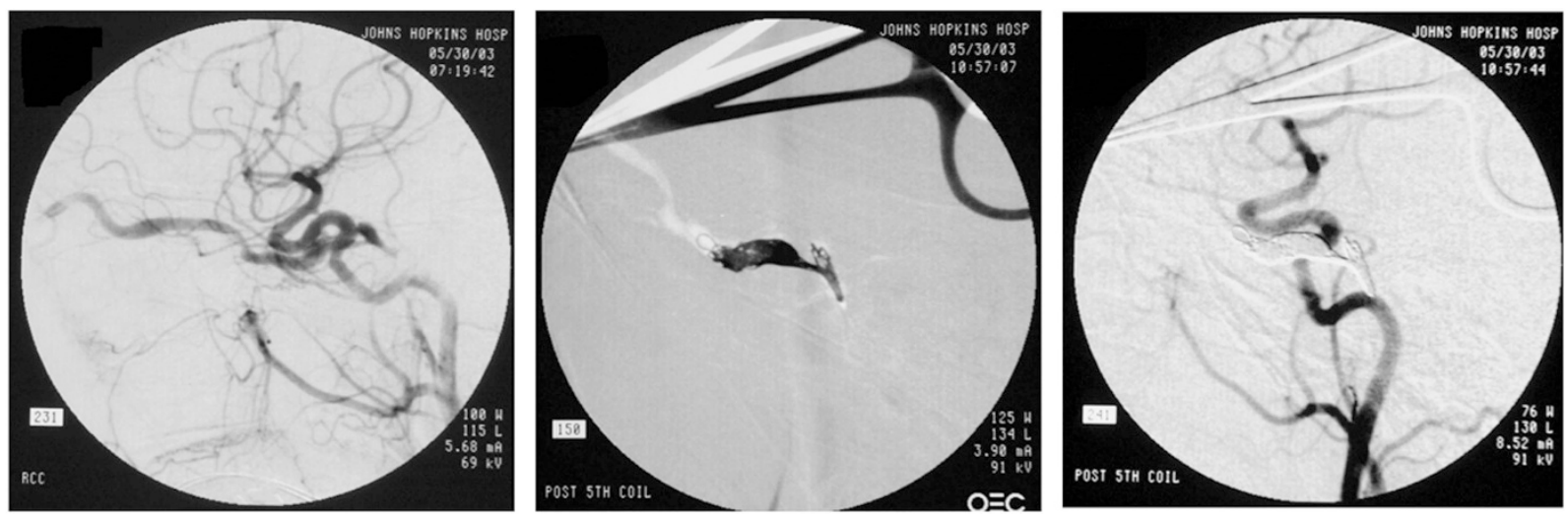

Figure 10 Successful closure of a dural CCF using a transvenous approach via the SOV. Prior to treatment, the common carotid arteriogram shows a dural CCF draining both anteriorly and posteriorly (left). After treatment, there are multiple platinum coils present within the fistula (middle). Post-procedure common carotid arteriogram shows obliteration of the fistula with intact flow in the ICA (right). 

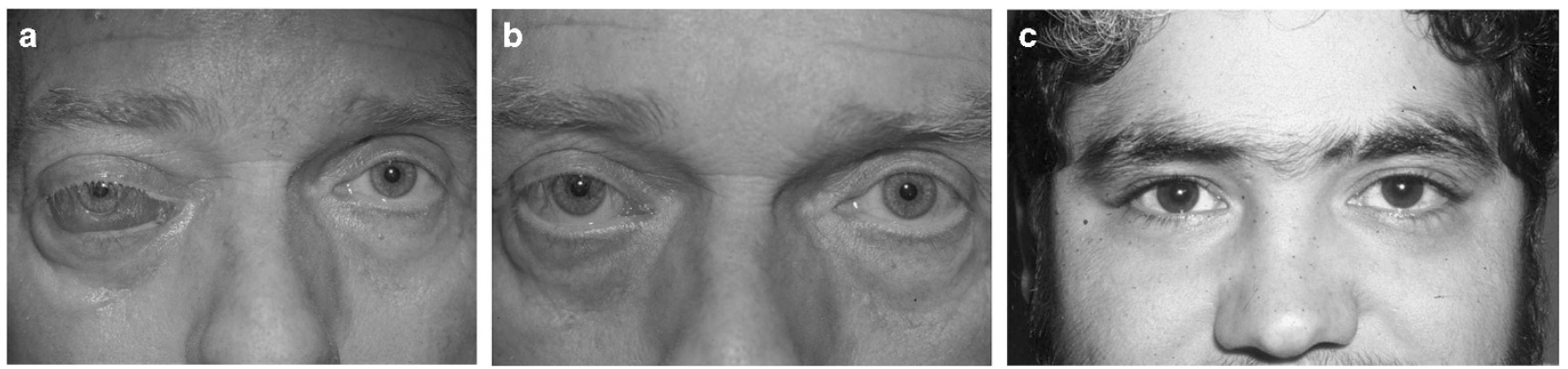

Figure 11 Improvement in visual manifestations after successful endovascular closure of direct (a, b) and dural (c) CCFs. (a, b) Pretreatment (a) and post-treatment (b) appearance of a patient with a post-traumatic right direct CCF. (c) Post-treatment appearance of the patient whose pretreatment appearance is seen in Figure 4.

venular variations or thrombosis, an SOV approach may be used. ${ }^{29}$ The SOV is approached via an anterior orbitotomy, and a venous catheter is then advanced through the SOV into the cavernous sinus. Although the majority of patients with a CCF have dilation of the SOV, an SOV that is fragile, small, thrombosed, or associated with other vascular anomalies (eg, varices) may elude cannulation. ${ }^{62}$ Nonetheless, success of this approach has been reported even in the setting of SOV thrombosis. ${ }^{54}$ When transvenous approaches are not feasible due to vessel tortuosity, or venous sinus thrombosis or occlusion, a direct orbital approach to the cavernous sinus with fluoroscopic guidance may be considered. ${ }^{58} \mathrm{~A}$ recent systematic review reported a $90 \%$ success rate with no major complications among CCF embolization procedures completed via an orbital approach. ${ }^{63}$ Coils commonly are used in transvenous procedures (Figure 10). Nylon-fibred platinum coils are preferred to bare platinum coils due to their improved thrombogenicity. ${ }^{61}$ Use of 3D rotational angiography, an emerging imaging technique, permits identification of the fistula point and downstream venous sac. This detailed anatomic characterization of the fistula may improve treatment planning for targeted embolization in the future. ${ }^{64}$

The success rate for transvenous procedures is $~ 80 \%$, albeit with a centre-dependent complication rate that ranges up to $20 \% .19,31,61,65,66$ Reported complications include ocular motor nerve palsies; trigeminal sensory neuropathy; brainstem infarction; significant IOP elevation; intracranial haemorrhage; pulmonary emboli; and orbital haemorrhage in the setting of the SOV or inferior ophthalmic vein approach. ${ }^{61,65-68}$ In addition, a case of inappropriate antidiuretic hormone secretion (SIADH) has been reported, which the authors attributed to disruption of posterior pituitary blood supply by the Onyx used for embolization. ${ }^{69}$ Although the risk involved necessitates careful patient selection, successful endovascular treatment can lead to marked improvement in signs and symptoms (Figure 11).
When an endovascular approach is not feasible or has been unsuccessful, stereotactic radiosurgery (SRS) may be considered for treatment of a dural CCF. Using a therapeutic radiation dose of 20-50 Gy, SRS induces an injury of the targeted vessel, thus obliterating the vessel lumen. It has the benefit of being less invasive than endovascular embolization, although the treatment effect is delayed by several months, which makes the procedure inappropriate for patients at risk for acute visual or neurological decompensation. Reports of complete resolution of a CCF with SRS treatment range from 50 to $100 \% .{ }^{36,70,71}$ The risk of immediate complications is low; however, data on late radiation-induced complications are limited. ${ }^{36}$

In conclusion, whether direct or dural, most CCFs can be diagnosed clinically. Invasive treatment usually is not required in most cases of low-flow fistulas, as these may close spontaneously. For patients with high-flow fistulas and those in which there is cortical venous drainage, successful closure usually can be achieved with an acceptably low morbidity and virtually no mortality using current endovascular techniques.

\section{Conflict of interest}

The authors declare no conflict of interest.

\section{References}

1 Barrow DL, Spector RH, Braun IF, Landman JA, Tindall SC, Tindall GT. Classification and treatment of spontaneous carotid-cavernous fistulas. J Neurosurg 1985; 62(2): 248-256.

2 Kashiwagi S, Tsuchida E, Goto K, Shiroyama Y, Yamashita T, Takahasi $\mathrm{M}$ et al. Balloon occlusion of a spontaneous carotidcavernous fistula in Ehlers-Danlos syndrome type IV. Surg Neurol 1993; 39(3): 187-190.

3 Masson-Roy J, Savard M, Mackey A. Carotid cavernous fistula in a patient with type IV Ehlers-Danlos syndrome. Can J Neurol Sci 2017; 44(4): 1-2.

4 Schievink WI, Piepgras DG, Earnest F, Gordon H. Spontaneous carotid-cavernous fistulae in Ehlers-Danlos syndrome type IV: case report. J Neurosurg 1991; 74(6): 991-998. 
5 Ono K, Oishi H, Tanoue S, Hasegawa H, Yoshida K, Yamamoto $\mathrm{M}$ et al. Direct carotid-cavernous fistulas occurring during neurointerventional procedures. Interv Neuroradiol 2016; 22(1): 91-96.

6 Kupersmith MJ, Berenstein A, Flamm E, Ransohoff J. Neuroophthalmologic abnormalities and intravascular therapy of traumatic carotid cavernous fistulas. Ophthalmology 1986; 93(7): 906-912.

7 Barr JD, Mathis JM, Horton JA. Iatrogenic carotid-cavernous fistula occurring after embolization of a cavernous sinus meningioma. AJNR Am J Neuroradiol 1995; 16(3): 483-485.

8 Guglielmi G, Vinuela F, Duckwiler G, Dion J, Stocker A. Highflow, small-hole arteriovenous fistulas: treatment with electrodetachable coils. AJNR Am J Neuroradiol 1995; 16(2): 325-328.

9 Kuether TA, O'Neill OR, Nesbit GM, Barnwell SL. Direct carotid cavernous fistula after trigeminal balloon microcompression gangliolysis: case report. Neurosurgery 1996; 39(4): 853-855.

10 Dolenc VV, Lipovsek M, Slokan S. Traumatic aneurysm and carotid-cavernous fistula following transsphenoidal approach to a pituitary adenoma: treatment by transcranial operation. Br J Neurosurg 1999; 13(2): 185-188.

11 Song IC, Bromberg BE. Carotid-cavernous sinus fistula occurring after a rhinoplasty. Case report. Plast Reconstr Surg 1975; 55(1): 92-96.

12 Lister JR, Sypert GW. Traumatic false aneurysm and carotidcavernous fistula: a complication of sphenoidotomy. Neurosurgery 1979; 5(4): 473-475.

13 Pedersen RA, Troost BT, Schramm VL. Carotid-cavernous sinus fistula after external ethmoid-sphenoid surgery. Clinical course and management. Arch Otolaryngol 1981; 107 (5): 307-309.

14 Reilly Jr JJ, Caparosa RJ, Latchaw RE, Sheptak PE. Aberrant carotid artery injured at myringotomy. Control of hemorrhage by a balloon catheter. JAMA 1983; 249(11): 1473-1475.

15 Feuerman TF, Hieshima GB, Bentson JR, Batzdorf U. Carotid-cavernous fistula following nasopharyngeal biopsy. Arch Otolaryngol 1984; 110(6): 412-414.

16 Habal MB. A carotid cavernous sinus fistula after maxillary osteotomy. Plast Reconstr Surg 1986; 77(6): 981-987.

17 Miller NR. Carotid-cavernous fistulas. In: Miller NR, Newman NJ, Biousse V, Kerrison JB (eds). Walsh and Hoyt's Clinical Neuro-ophthalmology 2. Lippincott-Williams \& Wilkins: Baltimore, MD, USA, 2005, pp 2263-2296.

18 Debrun GM, Vinuela F, Fox AJ, Davis KR, Ahn HS. Indications for treatment and classification of 132 carotidcavernous fistulas. Neurosurgery 1988; 22(2): 285-289.

19 Meyers PM, Halbach VV, Dowd CF, Lempert TE, Malek AM, Phatouros CC et al. Dural carotid cavernous fistula: definitive endovascular management and long-term follow up. Am J Ophthalmol 2002; 134(1): 85-92.

20 Ellis JA, Goldstein H, Connolly ES, Meyers PM. Carotidcavernous fistulas. Neurosurg Focus 2012; 32(5): E9.

21 Zhang Y, Zheng H, Zhou M, He L. Teaching NeuroImages: carotid-cavernous fistula caused by fibromuscular dysplasia. Neurology 2014; 82(15): e134-e135.

22 Miller NR. Diagnosis and management of dural carotidcavernous sinus fistulas. Neurosurg Focus 2007; 23(5): 1-15.

23 Taki W, Nakahara I, Nishi S, Yamashita K, Sadatou A, Matsumoto $\mathrm{K}$ et al. Pathogenetic and therapeutic considerations of carotid-cavernous sinus fistulas. Acta Neurochir (Wien) 1994; 127(1-2): 6-14.

24 Robert T, Sylvestre P, Blanc R, Botta D, Ciccio G, Smajda S et al. Thrombosis of venous outflows of the cavernous sinus: possible aetiology of the cortical venous reflux in case of indirect carotid-cavernous fistulas. Acta Neurochir (Wien) 2017; 159(5): 835-843.

25 Houser OW, Campbell JK, Campbell RJ, Sundt TMJ. Arteriovenous malformation affecting the transverse dural venous sinus-an acquired lesion. Mayo Clin Proc 1979; 54(10): 651-661.

26 Newton TH, Hoyt WF. Dural arteriovenous shunts in the region of the cavernous sinus. Neuroradiology 1970; 1: 71-81.

27 Srinivas HV, Murthy S, Brown R. Is Valsalva manoeuvre useful in diagnosing dural caroticocavernous fistulas? Eye (Lond) 2005; 19(11): 1226-1227.

28 Adam CR, Shields CL, Gutman J, Kim HJ, Hayek B, Shore JW et al. Dilated superior ophthalmic vein: Clinical and radiographic features of 113 cases. Ophthal Plast Reconstr Surg 2017; e-pub ahed of print 30 January 2017; doi:10.1097/ IOP.0000000000000872.

29 Miller NR, Monsein LH, Debrun GM, Tamargo RJ, Nauta HJW. Treatment of carotid-cavernous fistulas using a superior ophthalmic vein approach. J Neurosurg 1995; 83: 838-842.

30 Nomura M, Mori K, Tamase A, Kamide T, Seki S, Iida Y et al. Cavernous sinus dural arteriovenous fistula patients presenting with headache as an initial symptom. J Clin Med Res 2016; 8(4): 342-345.

31 Pashapour A, Mohammadian R, Salehpour F, Sharifipour E, Mansourizade R, Mahdavifard A et al. Long-term endovascular treatment outcome of 46 patients with cavernous sinus dural arteriovenous fistulas presenting with ophthalmic symptoms. A non-controlled trial with clinical and angiographic follow-up. Neuroradiol J 2014; 27(4): 461-470.

32 Woolen S, Gemmete JJ, Pandey AS, Chaudhary N. Dural carotid-cavernous fistula presenting with confusion and expressive aphasia. J Clin Neurosci 2015; 22(11): 1844-1846.

33 de Keizer RJW. Carotid-cavernous and orbital arteriovenous fistulas: ocular features, diagnostic, and hemodynamic considerations in relation to visual impairment and morbidity. Orbit 2003; 22(2): 121-142.

34 Golnik KC, Miller NR. Diagnosis of cavernous sinus artenovenous fistula by measurement of ocular pulse amplitude. Ophthalmology 1992; 99(7): 1146-1152.

35 Lewis AI, Tomsick TA, Tew JM Jr. Management of 100 Consecutive Direct carotid-cavernous fistulas: results of treatment with detachable balloons. Neurosurgery 1995; 36(2): 239-245.

36 Park SH, Park KS, Kang DH, Hwang JH, Hwang SK. Stereotactic radiosurgery for dural carotid cavernous sinus fistulas. World Neurosurg 2017; 106: 836-843.

37 Keltner JL, Satterfield D, Dublin AB, Lee BCP. Dural and carotid cavernous sinus fistulas. Ophthalmology 1987; 94(12): 1585-1600.

38 Chen CC-C, Chang PC-T, Shy C-G, Chen W-S, Hung H-C. $\mathrm{CT}$ angiography and MR angiography in the evaluation of carotid cavernous sinus fistula prior to embolization: a comparison of techniques. AJNR Am J Neuroradiol 2005; 26: 2349-2356.

39 Dos Santos D, Monsignore LM, Nakiri GS, Cruz AA, Colli BO, Abud DG. Imaging diagnosis of dural and direct cavernous carotid fistulae. Radiol Bras 2014; 47(4): 251-255.

40 Lang M, Habboub G, Mullin JP, Rasmussen PA. A brief history of carotid-cavernous fistula. J Neurosurg 2017; 126(6): 1995-2001. 
41 Gemmete JJ, Ansari SA, Gandhi D. Endovascular treatment of carotid cavernous fistulas. Neuroimaging Clin N Am 2009; 19(2): 241-255.

42 Debrun GM. Angiographic workup of a carotid cavernous sinus fistula (CCF) or what information does the interventionalist need for treatment? Surg Neurol 1995; 44: 75-79.

43 Andrade G, Ponte de Souza ML, Marques R, Silva JL, Abath $\mathrm{C}$, Azevedo-Filho HR. Endovascular treatment of traumatic carotid cavernous fistula with balloon-assisted sinus coiling. A technical description and initial results. Interv Neuroradiol 2013; 19(4): 445-454.

44 Halbach VV, Higashida RT, Barnwell SL, Dowd CF, Hieshima GB. Transarterial platinum coil embolization of carotid-cavernous fistulas. Am J Neuroradiol 1991; 12(3): 429-433.

45 Ohlsson M, Consoli A, Rodesch G. Endovascular treatment of carotico-cavernous fistulas with acrylic glue: a series of nine cases. Neuroradiology 2016; 58(12): 1181-1188.

46 Ogilvy CS, Motiei-Langroudi R, Ghorbani M, Griessenauer CJ, Alturki AY, Thomas AJ. Flow diverters as a useful adjunct to traditional endovascular techniques in the treatment of direct carotid-cavernous fistulas. World Neurosurg 2017; 105: 812-817.

47 Ducruet AF, Albuquerque FC, Crowley RW, McDougall CG. The evolution of endovascular treatment of carotid cavernous fistulas: a single-center experience. World Neurosurg 2013; 80(5): 538-548.

48 Higashida RT, Halbach VV, Tsai FY, Norman D, Pribram HF, Mehringer $\mathrm{CM}$ et al. Interventional neurovascular treatment of traumatic carotid and vertebral artery lesions: results in 234 cases. Am J Roentgenol 1989; 153(3): 577-582.

49 Kupersmith MJ, Berenstein A, Choi IS, Warren F, Flamm E. Management of nontraumatic vascular shunts involving the cavernous Sinus. Ophthalmology 1988; 95(1): 121-130.

50 Bink A, Goller K, Luchtenberg M, Neumann-Haefelin T, Dutzmann S, Zanella F et al. Long-term outcome after coil embolization of cavernous sinus arteriovenous fistulas. AJNR Am J Neuroradiol 2010; 31(7): 1216-1221.

51 Liu H, Wang Y, Chen Y, Cheng J, Yip P, Tu Y. Long-term clinical outcome of spontaneous carotid cavernous sinus fistulae supplied by dural branches of the internal carotid artery. Neuroradiology 2001; 43(11): 1007-1014.

52 Kai Y. Treatment of cavernous sinus dural arteriovenous fistulae by external manual carotid compression. Neurosurgery 2007; 60(2): 253-257.

53 Cruz JP, van Dijk R, Krings T, Agid R. Ophthalmic vein compression for selected benign low- flow cavernous sinus dural arteriovenous fistulas. J Neurosurg 2013; 119: 239-242.

54 Guven Yilmaz S, Yazici B, Cetinkaya A, Yagci A. Embolization of dural carotid-cavernous fistulas via the thrombosed superior ophthalmic vein. Ophthal Plast Reconstr Surg 2013; 29(4): 272-276.

55 Arat A, Cekirge S, Saatci I, Ozgen B. Transvenous injection of Onyx for casting of the cavernous sinus for the treatment of a carotid-cavernous fistula. Neuroradiology 2004; 46(12): 1012-1015.

56 Wakhloo AK, Perlow A, Linfante I, Sandhu JS, Cameron J, Troffkin $\mathrm{N}$ et al. Transvenous n-butyl-cyanoacrylate infusion for complex dural carotid cavernous fistulas: technical considerations and clinical outcome. AJNR Am J Neuroradiol 2005; 26: 1888-1897.
57 Mazal PR, Stichenwirth M, Gruber A, Sulzbacher I, Hainfellner JA. Tissue reactions induced by different embolising agents in cerebral arteriovenous malformations: a histopathological follow-up. Pathology 2006; 38(1): 28-32.

58 Elhammady MS, Peterson EC, Aziz-Sultan MA. Onyx embolization of a carotid cavernous fistula via direct transorbital puncture. J Neurosurg 2011; 114: 129-132.

$59 \mathrm{Hu}$ YC, Newman CB, Dashti SR, Albuquerque FC, McDougall CG. Cranial dural arteriovenous fistula: transarterial Onyx embolization experience and technical nuances. J Neurointerv Surg 2011; 3(1): 5-13.

60 Chen CJ, Mastorakos P, Caruso JP, Ding D, Schmitt PJ, Buell TJ et al. Transorbital approach for endovascular ccclusion of carotid-cavernous fistulas: technical note and review of the literature. Cureus 2017; 9(1): e976.

61 Kirsch M, Henkes H, Liebig T, Weber W, Esser J, Golik S et al. Endovascular management of dural carotid-cavernous sinus fistulas in 141 patients. Neuroradiology 2006; 48(7): 486-490.

62 Leibovitch I, Modjtahedi S, Duckwiler GR, Goldberg RA. Lessons learned from difficult or unsuccessful cannulations of the superior ophthalmic vein in the treatment of cavernous sinus dural fistulas. Ophthalmology 2006; 113(7): 1220-1226.

63 Phan K, Xu J, Leung V, Teng I, Sheik-Ali S, Maharaj M et al. Orbital approaches for treatment of carotid cavernous fistulas: a systematic review. World Neurosurg 2016; 96: 243-251.

64 Kannath SK, Rajan JE, Sarma SP. Anatomical localization of the cavernous sinus dural fistula by 3D rotational angiography with emphasis on clinical and therapeutic implications. J Neuroradiol 2017; 44(5): 326-332.

65 Yoshida K, Melake M, Oishi H, Yamamoto M, Arai H. Transvenous embolization of dural carotid cavernous fistulas: a series of 44 consecutive patients. AJNR Am J Neuroradiol 2010; 31(4): 651-655.

66 Kim DJ, Kim DI, Suh SH, Kim J, Lee SK, Kim EY et al. Results of transvenous embolization of cavernous dural arteriovenous fistula: a single-center experience with emphasis on complications and management. AJNR Am J Neuroradiol 2006; 27: 2078-2082.

67 Devoto MH, Egbert JE, Tomsick TA, Kulwin DR. Acute exophthalmos during treatment of a cavernous sinus-dural fistula through the superior ophthalmic vein. Arch Ophthalmol 1997; 115: 823-824.

68 Wladis EJ, Peebles TR, Weinberg DA. Management of acute orbital hemorrhage with obstruction of the ophthalmic artery during attempted coil embolization of a dural arteriovenous fistula of the cavernous sinus. Ophthal Plast Reconstr Surg 2007; 23(1): 57-59.

69 Chen T, Kalani MY, Ducruet AF, Albuquerque FC, McDougall CG. Development of syndrome of inappropriate antidiuretic hormone secretion (SIADH) after Onyx embolisation of a cavernous carotid fistula. J Neurointerv Surg 2017; 9(1): e3.

70 Chong GT, Mukundan S, Kirkpatrick JP, Zomorodi A, Sampson JH, Bhatti MT. Stereotactic radiosurgery in the treatment of a dural carotid-cavernous fistula. J Neuroophthalmol 2010; 30(2): 138-144.

71 Barcia-Salorio JL, Soler F, Barcia JA, Hernandez G. Stereotactic radiosurgery for the treatment of low-flow carotid-cavernous fistulae: results in a series of 25 cases. Stereotact Funct Neurosurg 1994; 63: 266-270. 